\title{
RELAÇÃO ENTRE O PRAXEMA E AS INTERAÇÕES MOTRIZES: IM- PLICAÇÕES NOS PROCESSOS DE LEITURA DE JOGO E TOMADA DE DECISÃO NOS JOGOS ESPORTIVOS ${ }^{1}$
}

\author{
Raquel Valente de Oliveira \\ Universidade Federal de Santa Maria, Santa Maria, Rio Grande do Sul, Brasil \\ João Francisco Magno Ribas \\ Universidade Federal de Santa Maria, Santa Maria, Rio Grande do Sul, Brasil \\ Pierre Normando Gomes-da-Silva \\ Universidade Federal da Paraíba, Paraíba, João Pessoa, Brasil
}

\begin{abstract}
Resumo
A Praxiologia Motriz consiste em uma teoria científica que visa analisar o funcionamento das práticas motrizes, abordando conhecimentos referentes a sua lógica interna, como o praxema, modelo operacional relativo ao processo comunicativo dos jogadores. Desse modo, essa pesquisa objetiva relacionar o praxema com as interações motrizes de comunicação e contracomunicação e apontar suas implicações nos processos de leitura de jogo e tomada de decisão nos Jogos Esportivos de cooperação e oposição. Para isso, realizou-se uma pesquisa teórica, de cunho exploratório, por meio do qual constatou-se que o praxema auxilia ou dificulta a leitura de jogo e a tomada de decisão, dependendo da interação motriz estabelecida entre os jogadores, apresentando-se como um importante elemento para atuar no jogo.
\end{abstract}

Palavras-chave: Praxema. Praxiologia Motriz. Interações motrizes. Jogos Esportivos.

\section{Introdução}

O esporte é uma das manifestações culturais mais difundidas socialmente e apresentase como fenômeno sociocultural de grande relevância para a humanidade. Conforme explicitam Greco e Benda (2001), o esporte manifesta-se com diferentes vieses no contexto social, como no lazer, na prevenção da saúde, no cenário escolar, na recuperação e reabilitação e no alto rendimento. Corroborando esse entendimento, Pimentel, Galatti e Paes (2010) descrevem que, atualmente, o esporte apresenta-se como um fenômeno globalizado e motivador de eventos internacionalmente reconhecidos, cenário de manifestações políticas e de poder, além de envolver grupos específicos em acontecimentos locais, com diferentes propósitos.

Como área de conhecimento, a Praxiologia Motriz prende-se em analisar sistematicamente o funcionamento do jogo em suas diferentes manifestações culturais, de modo a construir instrumentos de análise que permitam conhecer seu funcionamento. Sendo assim, a Praxiologia Motriz, criada pelo professor Pierre Parlebas, desde os anos 1970, apresenta-se como uma ferramenta sistemática que objetiva desvelar a lógica interna das práticas motrizes a par-

\footnotetext{
${ }^{1} \mathrm{O}$ presente estudo contou com apoio financeiro do Programa Institucional de Bolsas de Iniciação Científica (PROBIC) da FAPERGS.
} 
tir de suas regras. Parlebas (2001) compreende toda modalidade esportiva ou lúdica como sistemas praxiológicos, apresentando uma estrutura e uma lógica interna particulares, constituídas por um conjunto de elementos com distintas características.

Conforme Lagardera e Lavega (2003), a lógica interna é o modo no qual estão preestabelecidas as ações motrizes ${ }^{2}$ de todos os jogos e esportes, tornando-se possível por intermédio dela conhecer as interações estabelecidas entre os jogadores e as ações motrizes derivadas do sistema praxiológico. As regras ou normas de funcionamento configuram a lógica interna das práticas motrizes e orientam a ação motriz dos jogadores. Além disso, segundo Parlebas (2001), o sistema de regras estabelece a maneira como os jogadores devem se relacionar com os demais participantes, com os materiais, com o espaço utilizado e como deverão ajustar-se ao tempo de jogo, sendo estes os quatro pilares básicos da lógica interna.

Ao considerar a categorização dos esportes, os Jogos Esportivos (JEs) ${ }^{3}$ diferem-se das demais práticas esportivas por vários aspectos específicos de sua lógica interna, dentre eles, destaca-se a relação com os demais jogadores. De acordo com Parlebas (2001, p. 276), os Jogos Esportivos definem-se pela "situação motriz de enfrentamento codificado, denominado 'jogo' ou 'esporte' pelas instâncias sociais. Cada jogo esportivo se define por um sistema de regras que determina sua lógica interna". Ainda segundo o autor, há duas categorias de Jogos Esportivos: os Jogos Esportivos Institucionais, que são os esportes internacionalmente institucionalizados, com regras fixas, e os Jogos Esportivos Tradicionais, práticas competitivas, porém não institucionalizadas, as quais apresentam regras flexíveis, possíveis de serem adaptadas.

Ao longo dos anos, algumas modalidades pertencentes aos JEs apresentaram alterações no que diz respeito a suas regras, e, assim, consequentemente, a lógica interna dessas modalidades sofreu algumas modificações (COSTA, 1999). Essas práticas motrizes foram aperfeiçoando-se devido às exigências técnico-táticas advindas das competições de alto nível. No cenário esportivo atual, percebe-se que somente as capacidades físicas, como a velocidade e a força, passaram a ser insuficientes para acompanhar o desenvolvimento e o aperfeiçoamento técnico-tático dos atletas de alto rendimento.

Por conseguinte, essas exigências demandaram algumas alterações no sistema de regras de cada modalidade, além de avanços no que diz respeito à organização tática das equipes, bem como na criação e na evolução de jogadas, na inteligência tática dos atletas, na leitura de jogo, na antecipação, na tomada de decisão, dentre outros aspectos que se tornaram imprescindíveis para o desempenho dos jogadores. A origem do líbero no voleibol é um dos exemplos que corrobora essa premissa, uma vez que esse papel foi criado devido à demanda por um especialista responsável pela recepção e pela defesa da equipe, pois o saque e o ataque, em algumas situações, apresentavam superioridade em relação a esses momentos (MATIAS; GRECO, 2011). No que diz respeito ao aperfeiçoamento técnico-tático, o saque também entrou em constante progresso em virtude do aprimoramento da recepção, por meio do líbero, que, consequentemente, dificultava o sistema defensivo da equipe (bloqueio e defesa) (VICARI; VERMELHO; VIANA, 2012).

Portanto, além das capacidades físicas e das habilidades técnicas, atualmente, tornouse imprescindível que os jogadores dessas modalidades, desde equipes escolares até profissionais, levem em consideração os aspectos supracitados relacionados ao contexto do jogo, que

\footnotetext{
${ }^{2}$ A ação motriz constitui a unidade básica de análise da Praxiologia Motriz, a qual representa as propriedades emergentes do sistema praxiológico (LAGARDERA; LAVEGA, 2003).

${ }^{3}$ Foi adotada a nomenclatura "Jogos Esportivos" pelo fato de que se utilizou, na elaboração do artigo, como aporte teórico, os conceitos da Praxiologia Motriz, indo ao encontro da proposta de Parlebas, autor base neste estudo. No entanto, a partir dos objetivos da pesquisa, serão considerados apenas os esportes que apresentam interações de cooperação e oposição entre os jogadores, nos quais enquadram-se o basquetebol, o futebol, o futsal, o handebol, o rugby e o voleibol, por exemplo.
} 
são essenciais para obter êxito perante as diferentes situações motrizes. Sendo assim, a Praxiologia Motriz defende que o jogador deve assimilar e desenvolver alguns princípios e relações táticas de jogo e, para isso, apresenta modelos que estruturam e oferecem subsídios norteadores para compreender as especificidades e as características dos JEs. Dentre esses modelos, está o praxema.

O praxema corresponde à "conduta motriz ${ }^{4}$ de um jogador interpretada como um signo, cujo significante é o comportamento observável e cujo significado é o projeto tático correspondente ao dito comportamento, tal e como é percebido" (PARLEBAS, 2001, p. 349). Para exemplificar essa definição, o autor se refere ao basquetebol, discorrendo sobre o fato de que, quando uma equipe dispõe da posse de bola e um de seus jogadores corre pela lateral da quadra, esta imagem da ação representa o "significante" de um signo (oriunda de sua orientação e leitura corporal, espaço de corrida e aceleração). Seu companheiro de equipe que retém a bola interpretará esse signo como um pedido de passe, sendo ele o "significado" do comportamento do jogador. Com isso, pode-se afirmar que o significante é o sinal que está associado a uma mensagem, sendo ela o significado da ação. A combinação entre o significante comportamental do jogador e seu significado constitui o praxema (PARLEBAS, 2001).

Ao encontro disso, Lagardera e Lavega (2003) observam que, além de realizar a leitura dos praxemas dos jogadores, é necessário fazer a leitura do contexto do jogo e das ações de companheiros e adversários e interpretar as ações motrizes e as mensagens emitidas pelos demais jogadores, de modo a antecipar-se, seja com o intuito de cooperar ou se opor, para posteriormente tomar as melhores decisões no jogo. A mercê desse entendimento, essa pesquisa propõe relacionar o praxema com as interações motrizes de comunicação e contracomunicação e apontar suas implicações nos processos de leitura de jogo e tomada de decisão nos Jogos Esportivos de cooperação e oposição.

Constata-se, por meio da literatura nacional e internacional empregada, que ao fazer referência aos JEs, aborda-se sobre diversos conhecimentos inerentes a essas práticas motrizes, como, por exemplo, a leitura de jogo, as ações técnicas, os sistemas táticos e a tomada de decisão. No entanto, outros conhecimentos como os praxemas são também notoriamente essenciais para o jogo, tendo em vista a atuação dos participantes no contexto esportivo. Além disso, percebe-se que quase não há pesquisas acerca do praxema, tão pouco relativo aos JEs, sendo insuficientemente abordados em pesquisas científicas da área, visto sua importância nas interações motrizes de cooperação e oposição e nos processos de leitura de jogo e tomada de decisão. Por esse motivo, verificou-se que o tema em questão carece, primeiramente, de um aprofundamento teórico para, posteriormente, ir-se a campo e realizar estudos aplicados, por meio de observações, por exemplo. Assim, ao identificar a necessidade de posteriores pesquisas de campo sobre o praxema, torna-se importante o aprofundamento desse estudo com futuros questionamentos sobre os praxemas nos Jogos Esportivos, como também nas demais práticas motrizes.

\section{Metodologia}

Para alcançar os objetivos do estudo realizou-se uma pesquisa teórica, pois utilizou-se de obras já elaboradas como livros, artigos científicos e periódicos especializados sobre o tema. Para Demo (1995), a pesquisa teórica caracteriza-se em estudar teorias, formular referências e aprimorar conceitos. Além disso, esse estudo consiste em uma pesquisa de cunho exploratório que tem como principal objetivo "desenvolver, esclarecer e modificar conceitos e ideias, tendo em vista a formulação de problemas mais precisos ou hipóteses pesquisáveis para estudos posteriores" (GIL, 2008, p. 27).

\footnotetext{
${ }^{4}$ Para Parlebas (2001, p. 85) a conduta motriz é "o comportamento motor enquanto portador de significado", sendo as ações motrizes pessoais dos jogadores. 
$\mathrm{Na}$ busca pela delimitação do referencial teórico, empregou-se os critérios propostos por Salvador (1986), sendo eles: parâmetro temático, parâmetro linguístico, principais fontes e parâmetro cronológico. Em relação ao parâmetro temático e às principais fontes, foram consideradas obras bibliográficas que discorrem sobre o praxema nas mais diferentes práticas motrizes, essencialmente nos Jogos Esportivos, além de obras acerca da Praxiologia Motriz e seus conhecimentos, como os Universais, as interações motrizes, a leitura de jogo e a tomada de decisão, especialmente as que se designam aos JEs.

Considerando o parâmetro linguístico, foram selecionadas e analisadas obras da literatura nacional, além de obras em espanhol por serem bases teóricas clássicas referentes à Praxiologia Motriz. Em relação ao parâmetro cronológico, optou-se por não delimitar o referencial teórico por meio de um recorte temporal, para não perder informações essenciais contribuintes para o desenvolvimento da pesquisa. É importante salientar que não foi delimitado o número de produções científicas a serem analisadas e utilizadas na pesquisa, uma vez que isso poderia excluir informações primordiais para sua elaboração.

Para atingir o objetivo da pesquisa, foram empregados estudos que vêm a consolidar a relação entre o praxema e as interações motrizes e suas implicações nos processos de leitura de jogo e tomada de decisão nos JEs de cooperação e oposição, apresentando considerações e elementos pertinentes para o referencial teórico e os resultados da pesquisa. Com base nessas referências, inicialmente, foram levantados e interpretados os conceitos básicos acerca da Praxiologia Motriz e do praxema. Logo após, estabeleceu-se a relação dessas temáticas, tendo em vista os processos de leitura de jogo e de tomada de decisão, utilizando como aporte praxiológico o Sistema de Classificação CAI para discorrer sobre as interações motrizes de comunicação e contracomunicação nos Jogos Esportivos de cooperação e oposição.

Para situar o praxema, utilizou-se dos Universais que, por sua vez, apresentam-se como um instrumento de análise proposto pela Praxiologia Motriz, para detalhar e compreender o universo das diferentes manifestações culturais, no qual caracterizam-se como modelos operacionais que representam a estrutura básica de funcionamento das práticas motrizes (PARLEBAS, 2001). Por meio desses modelos, torna-se possível desvelar e ampliar o entendimento acerca da lógica interna de cada modalidade pertencente aos JEs.

Os Universais são divididos em sete modelos, criados a partir de critérios relativos à interação entre os participantes, às formas de pontuação, às funções exercidas no jogo e às formas de comunicação entre os jogadores. São eles: Rede de Comunicação Motriz, Rede de Interação de Marca, Sistema de Pontuação, Papel Sociomotor, Subpapel Sociomotor, Gestema e Praxema (PARLEBAS, 2001). Vale destacar que os sete modelos dos Universais são de suma relevância para conhecer a essência e o funcionamento dos JEs e das demais práticas motrizes. No entanto, nesta pesquisa, destacou-se e abordou-se, como objeto principal, o praxema, por ser o tema central do estudo.

\section{Resultados e discussão}

Para Uribe Pareja (1997, p. 72) os praxemas são "ações motrizes dos jogadores que indicam o início ou continuidade de algumas situações práticas de jogo", sendo o praxema a parte integrante de uma ação motriz, manifestando-se por meio dela. Além disso, o praxema depende do sistema de regras da modalidade, pois ele, assim como os demais modelos dos Universais, depende diretamente da lógica interna do jogo, bem como do nível de competência e de habilidade dos participantes, podendo alterar-se em razão dessas variantes (LAGARDERA; LAVEGA, 2003).

A observação, a leitura e a interpretação dos praxemas são processos complexos, principalmente em etapas de iniciação esportiva, tendo em vista que sua leitura pode ser realizada diferentemente pelos participantes, inclusive mediante uma mesma situação de jogo. Isso 
ocorre pelo fato de que a conduta motriz manifesta as características pessoais e particulares do indivíduo, emitindo, portanto, praxemas próprios do jogador e divergentes dos demais. Além disso, quando são remetidos aos adversários, os praxemas comportam mensagens obscuras que induzem a uma leitura inversa e/ou equivocada da ação motriz do jogador, característica da interação motriz de oposição.

Partindo da premissa que toda prática motriz constitui um sistema no qual o participante se relaciona com o entorno físico e com os demais jogadores, a Praxiologia Motriz apresenta o Sistema de Classificação CAI, que permite evidenciar o funcionamento das modalidades, caracterizando-se como um instrumento de análise. O Sistema de Classificação CAI tem por finalidade classificar as mais diferentes práticas motrizes e caracterizá-las conforme a presença ou a ausência de interação motriz entre companheiros (C) e/ou entre adversários (A) e a relação com o entorno físico, podendo este ser ou não incerto (I) (PARLEBAS, 1987).

Desse modo, conforme o Sistema de Classificação CAI, as modalidades pertencentes aos JEs que foram consideradas na pesquisa (modalidades que apresentam companheiros e adversários) configuram-se como práticas sociomotrizes de cooperação e oposição, pelo fato de os jogadores manterem interações de comunicação entre companheiros de equipe e de contracomunicação entre adversários, realizadas em um meio físico padrão, pois ele sempre será regular e conhecido pelo participante. Para Ribas (2014), quanto melhor for a comunicação entre os jogadores, maior a possibilidade de êxito na tarefa para opor-se aos adversários, ampliando as alternativas táticas e, consequentemente, o processo de tomada de decisão demandado pelo jogo.

Lagardera e Lavega (2003) afirmam que as situações de cooperação e oposição correspondem às práticas equivalentes aos esportes de duelo coletivo, nos quais os jogadores dispõem da colaboração de companheiros e da oposição de adversários. Assim, Parlebas (2001) discorre que o praxema se manifesta em forma de cumplicidade com companheiros e de duplicidade com adversários, estando presentes a incerteza e a imprevisibilidade nas ações e na conduta motriz dos jogadores. Por essa razão, o praxema tem um papel fundamental no que diz respeito às interações motrizes estabelecidas entre os jogadores e à leitura das ações motrizes e das mensagens emitidas por companheiros e adversários.

Desse modo, em relação à comunicação motriz, as mensagens, as informações e os praxemas devem ser os mais claros possíveis aos companheiros de equipe. Concomitantemente, torna-se necessário que os jogadores conheçam as características de seus companheiros e sua linguagem expressa a partir do corpo (praxemas), para ler e interpretar com maior propriedade suas condutas motrizes. De tal forma, os jogadores devem saber as possíveis ações de seus companheiros quando estes se posicionam e movimentam-se de determinada maneira pelo espaço de jogo, ao retificar o movimento bruscamente, quando realizam deslocamentos e fintas, exemplos esses de praxemas manifestados nos diferentes JEs de cooperação e oposição, conforme a lógica interna de cada modalidade (basquetebol, futebol, futsal, handebol, rugby, voleibol, dentre outros).

No futsal, por exemplo, é essencial para a comunicação da equipe que os jogadores consigam identificar quais as prováveis ações que são realizadas quando seus companheiros manifestam determinados praxemas, como ocupar certos espaços da quadra ou trocar de direção repentinamente. Já no voleibol, cabe ao jogador saber interpretar o que normalmente o levantador de sua equipe faz quando orienta sua cabeça para trás ao realizar o levantamento por meio da ação motriz de toque, praxema esse importante para o processo comunicativo da equipe e para obter êxito nas situações de jogo.

Já em relação à contracomunicação motriz, os jogadores devem ler, interpretar e antecipar constantemente o comportamento motor, as ações motrizes e os praxemas de seus adversários, enviando-lhes mensagens obscuras, com o intuito de ludibriá-los. Segundo Ribas (2014), o caráter de oposição que caracteriza essa interação motriz torna incertos os praxemas 
que os adversários emitem no decorrer do jogo, pois são maximamente dificultados a seus oponentes. Contudo, é fundamental compreender que todos os jogadores são portadores de mensagens e, portanto, ao mesmo tempo em que o participante busca ler e interpretar os praxemas de seu oponente, seus próprios praxemas também são constantemente interpretados. Assim, selecionar as melhores estratégias para solucionar as situações-problema impostas pelo jogo e, para isso, dificultar ao máximo que seus adversários antecipem a sua decisão torna-se imprescindível.

À mercê desse entendimento, pode-se exemplificar a manifestação dos praxemas em diferentes situações motrizes das modalidades pertencentes aos JEs, estabelecidas a partir da interação motriz de oposição. Por exemplo, no handebol, quando o jogador executa a finta, estará emitindo um praxema relacionado à variação de sua direção pelo espaço da quadra. Isso induzirá a antecipação equivocada de seu oponente em relação à ação motriz realizada, tendo por objetivo se sobressair à marcação ou à defesa adversária. A finta também está altamente presente no rubgy e no basquetebol, no momento em que o jogador que está com a bola se desloca em direção à área de validação e à cesta, respectivamente, com a finalidade de progredir em campo/quadra para marcar o ponto. Já no voleibol, os bloqueadores precisam ler e interpretar constantemente os praxemas do levantador adversário (orientação da cabeça e retificação do movimento, por exemplo). Entretanto, para superar o bloqueio adversário, o atacante precisa emitir "falsos" praxemas, como posicionar seu corpo na diagonal e atacar na paralela, com o intuito de ludibriar os bloqueadores e os defensores adversários.

No que diz respeito às formas de analisar os praxemas manifestados no jogo, este estudo foi pautado na estruturação dos momentos de análise contemplada no livro de Ribas (2014). O autor faz uma reorganização da sistematização proposta no capítulo de Serenini, Freire e Noce (1998) da obra Iniciação esportiva universal (volume 2). Optou-se pela estrutura de Ribas (2014), por apresentar avanços acerca dos momentos de análise, ao considerar e introduzir conceitos da Praxiologia Motriz. Contudo, ainda se organizaram e adaptaram-se os três momentos de análise, de modo a destacar: Conhecimento Prévio, Análise Antecipada e Análise Situacional, tanto referente aos companheiros de equipe quanto aos adversários. A disposição e a consideração desses momentos de análise tornam-se importantes para a leitura dos praxemas dos jogadores e para o processo de tomada de decisão, além da análise dos espaços de jogo, do posicionamento e das características dos participantes.

O Conhecimento Prévio refere-se ao conhecimento das características das equipes e/ou de alguns jogadores específicos, o qual auxiliará no processo de leitura do jogo e no conhecimento mais preciso da conduta motriz dos jogadores, obtida por meio de vídeos e observações diretas. A Análise Antecipada diz respeito ao diagnóstico realizado pouco antes da execução da ação motriz, constituindo-se na primeira condição de análise acerca dos jogadores e de suas ações. Já a Análise Situacional caracteriza-se pela última leitura do jogador, realizada antes de executar determinada ação de jogo, quase que simultaneamente (RIBAS, 2014).

Com base nesse pressuposto, percebeu-se que os momentos de análise elucidados por Ribas (2014) foram remetidos apenas à contracomunicação motriz. No entanto, a partir dos conhecimentos da Praxiologia Motriz, vê-se a necessidade de referenciar o Conhecimento Prévio, a Análise Antecipada e a Análise Situacional também ao processo de comunicação motriz, pois, como já explicitado, ambas as interações são necessárias para que a equipe obtenha eficácia e um bom desempenho esportivo. Para isso, torna-se essencial que os jogadores conheçam previamente seus companheiros e adversários, facilitando, com isso, a leitura e a análise de seus praxemas e, consequentemente, o processo de tomada de decisão. Assim, tanto a comunicação quanto a contracomunicação motriz são primordiais para os processos de leitura de jogo, antecipação e tomada de decisão, bem como para a leitura praxêmica dos jogadores, conforme suas possibilidades de ação. 
Além disso, constatou-se que a manifestação dos praxemas nos JEs e em suas diferentes situações motrizes é principalmente evidenciada no momento da Análise Situacional, tanto por companheiros quanto por adversários, podendo estes serem facilitados ou dificultados dependendo da interação motriz estabelecida. Com isso, Ribas (2014) elucida alguns praxemas que são comumente manifestados no momento da Análise Situacional no voleibol, relat ivo à interação motriz de contracomunicação. Um de seus exemplos refere-se aos momentos do saque e da recepção, nos quais o sacador retifica seu movimento corporal no final da ação, com o intuito de desestruturar e surpreender a recepção adversária.

Em relação ao momento da defesa, para ocupar corretamente os espaços da quadra e tomar as melhores decisões, os defensores precisam ler os praxemas dos atacantes adversários, como o movimento do braço e da mão e a batida na bola, para assim posicionar-se mais próximos à rede (bola largada) ou mais recuados (ataque potente). $\mathrm{O}$ atacante, por sua vez, tentará dificultar e ludibriar ao máximo a ação dos defensores e sua interpretação praxêmica situacional, observando, a priori, o posicionamento corporal desses jogadores, além dos espaços vazios deixados por eles, principalmente atrás do bloqueio e no centro da quadra (RIBAS, 2014).

No entanto, ao se tratar da interação motriz de cooperação, no futebol torna-se essencial para a progressão da equipe em campo e para seu processo ofensivo que a linha de passe entre os jogadores seja estabelecida eficazmente. Para isso, eles precisam realizar a Análise Situacional e a leitura praxêmica de seu companheiro, como o posicionamento do tronco e de seus membros inferiores no momento do passe/recepção. Isso torna-se necessário principalmente em etapas de iniciação esportiva, nas quais os jogadores não têm entrosamento suficiente. Além disso, na maioria das vezes, há dificuldade em ler e interpretar os praxemas de seus companheiros, pois as ações de jogo ainda não estão suficientemente automatizadas e, por essa razão, a atenção fica centrada exclusivamente no gesto técnico, devido ao alto grau de dificuldade na execução das ações motrizes.

Nos JEs de cooperação e oposição, a leitura de jogo e a tomada de decisão apresentam-se como processos essenciais para estabelecer a comunicação e a contracomunicação motriz entre os jogadores. Utilizando o exemplo do voleibol, Matias (2009) observa que, ao realizar a leitura do jogo, por meio da cognição e a partir da seleção de respostas, o levantador deve levar em conta, simultaneamente, diversos elementos, como: a qualidade da recepção, se o passador está em condições de atacar, disponibilidade dos demais atacantes, determinação da movimentação do ataque, análise da formação do bloqueio adversário, verificação da disposição da defesa adversária e, por fim, escolha da melhor opção de ataque (tomada de decisão) em relação a todo o contexto do jogo.

Ao possibilitar a identificação de determinadas informações provenientes das ações dos jogadores, o praxema também propiciará a leitura do jogo em suas diferentes situações, conforme a lógica interna de cada prática motriz. Com isso, Ribas (2014) destaca que o praxema desempenha um importante papel nas interações motrizes estabelecidas entre os participantes, no processo de leitura de jogo, na antecipação motriz e na tomada de decisão. Além disso, segundo Graça e Mesquita (2007), a leitura de jogo é determinante para que o participante desenvolva o processo de tomada de decisão durante as situações motrizes, de acordo com o papel de cada um e suas possibilidades de ação.

A tomada de decisão, por sua vez, é a seleção de respostas mediante diferentes possibilidades, que se concretiza por meio da ação motriz propriamente dita (MATIAS; GRECO, 2010). Segundo Greco (2001), a tomada de decisão é caracterizada pela capacidade de resolver tarefas e situações-problema oriundas do jogo, advindas da atitude cognitiva do praticante. 


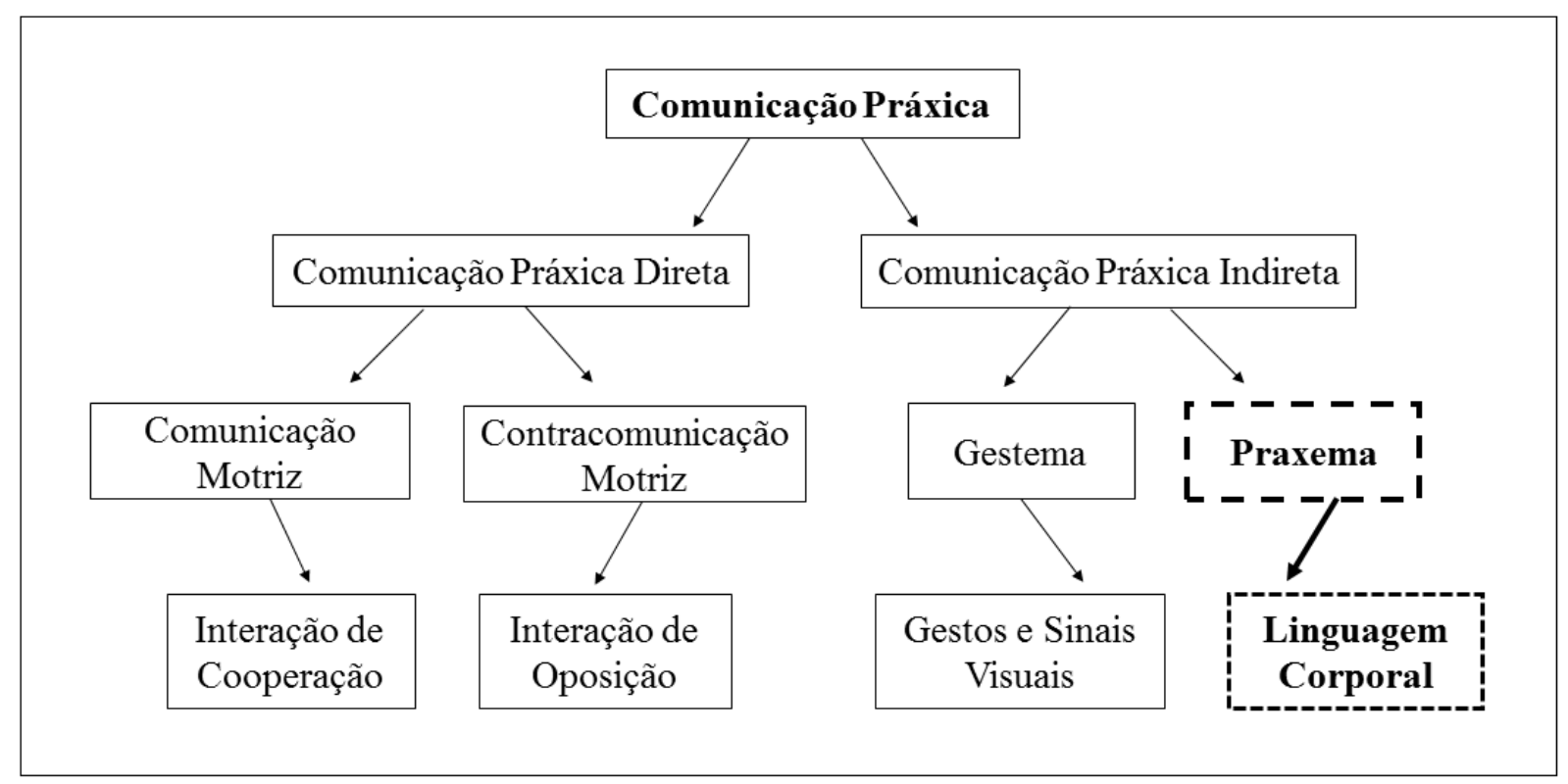

Figura 1 - Comunicação Práxica Direta e Indireta. Fonte: Adaptada de Parlebas (2001).

Nos JEs de cooperação e oposição, os jogadores estão em um constante processo de tomada de decisão devido, dentre outros aspectos, às incertezas do jogo resultantes das interações motrizes estabelecidas entre companheiros e adversários (JIMÉNEZ JIMÉNEZ, 2011).

Desse modo, a tomada de decisão ganha relevância nessas modalidades esportivas, pois, a todo o momento, é preciso adotar atitudes táticas e estratégicas em virtude das ações dos demais jogadores. Segundo Garganta e Oliveira (1996), para que o jogador tenha um bom desempenho esportivo, torna-se fundamental que disponha de uma boa capacidade de tomada de decisão. O êxito nas decisões está, dentre outros elementos, na leitura e na decodificação dos praxemas, processos esses dependentes, a priori, da percepção e da antecipação motriz.

Como elemento significativo para os processos de leitura de jogo e de tomada de decisão, a Comunicação Práxica apresenta-se como critério de classificação proposto pela Praxiologia Motriz, constituindo as características das diferentes situações sociomotrizes e de sua lógica interna (PARLEBAS, 2001). Assim, a Comunicação Práxica divide-se em duas categorias: Comunicação Práxica Direta e Comunicação Práxica Indireta. A Comunicação Práxica Direta é composta pela comunicação (cooperação) e pela contracomunicação (oposição), formas básicas de interações motrizes estabelecidas entre os jogadores.

A Comunicação Práxica Indireta constitui-se pelo gestema e pelo praxema. Nesse sentido, o gestema é a comunicação por meio de gestos, sinais visuais e códigos preestabelecidos que permitem a transmissão de mensagens de forma clara, facilitando a compreensão por parte dos companheiros e auxiliando na comunicação entre eles. No entanto, são também facilmente interpretados pelos adversários e, portanto, em níveis mais avançados, as emissões de mensagem passam a ocorrer de forma mais sutil. Já o praxema é a linguagem expressa a partir do corpo, sendo o comportamento de "pré-ação" dotado de uma mensagem tática ou relacional (LAGARDERA; LAVEGA, 2003).

Desse modo, nos Jogos Esportivos de cooperação e oposição, o entendimento das interações de comunicação e de contracomunicação, bem como a leitura gestêmica e praxêmica de companheiros e adversários, é elemento primordial para a leitura de jogo e para o processo de tomada de decisão. Ter conhecimento acerca desses elementos é de grande relevância para o contexto esportivo, pois a leitura de jogo pautada no entendimento das ações dos jogadores fica mais evidente e, dessa forma, possibilita a melhor tomada de decisão para resolver as situações defrontadas. Assim, torna-se necessário que o jogador tenha uma boa capacidade 
para ler os praxemas dos participantes, pautando suas ações motrizes a partir das interpretações realizadas por meio do processo de leitura de jogo.

\title{
Conclusões
}

A partir dos conhecimentos da Praxiologia Motriz e de seus instrumentos de análise, torna-se possível analisar a lógica interna das diferentes práticas motrizes, assim como também compreender os elementos e os conhecimentos necessários para sua prática. Embora cada modalidade que compõe os JEs tenha sua própria lógica interna, muitos elementos provenientes do jogo e fundamentais para ele se equivalem e devem ser similarmente levados em consideração no processo de ensino-aprendizagem-treinamento. Nessa perspectiva, o praxema apresenta-se como um desses importantes elementos, tendo em vista sua influência no que diz respeito às interações motrizes de comunicação e de contracomunicação estabelecidas entre os participantes dos Jogos Esportivos de cooperação e oposição e suas implicações nos processos de leitura de jogo e tomada de decisão.

Com base nesse entendimento, o professor-treinador deve proporcionar a seus jogadores estruturas de atividades que contemplem a leitura de jogo, destacando sempre alguns conhecimentos, como as interações motrizes estabelecidas, bem como a leitura, a interpretação e a antecipação de praxemas, para que eles consigam, conforme as possibilidades, tomar as melhores decisões. Assim, quanto melhor a interpretação das ações, melhores serão as alternativas para antecipar-se às diferentes situações do jogo e, assim, atingir o sucesso tático.

Vale ainda ressaltar que o objetivo desta pesquisa não era delimitá-la a um único âmbito específico, pois os conceitos abordados podem ser empregados tanto no ensino escolar quanto no processo de treinamento esportivo. Cabe, portanto, ao leitor direcionar sua prática pedagógica a partir do contexto no qual está inserido e do nível de aprendizagem dos jogadores, utilizando-se de artifícios metodológicos que oportunizem e instiguem o desenvolvimento dos elementos e conhecimentos supracitados.

\section{RELATION BETWEEN PRAXEMA AND MOTOR INTERACTIONS: IMPLICA- TIONS IN GAME READING PROCESS AND DECISION MAKING IN SPORTS'S GAMES}

\begin{abstract}
The Motor Praxeology consist in a scientific theory, which aims to analyse operation of motor practises, approaching knowledge about their internal logic, as the praxema, operational model for communicative process of players. Thus, this research aims to relate the praxema with motor interactions of communication and counter-communication, and to appoint them implications in game reading process and decision making in Sports's Games of cooperation and opposition. For this, we performed an exploratory theoretical research, wherewith we verified that praxema assists or hinders game reading and decision making, depending on of motor interaction established between players, presenting itself as an important element to act in game.
\end{abstract}

Keywords: Praxema. Motor Praxeology. Motor Interactions. Sports’s Games. 


\section{RELACIONES ENTRE EL PRAXEMA Y LAS INTERACCIONES MOTRICES: IM- PLICACIONES EN LOS PROCESOS DE LECTURA DE JUEGO Y TOMA DE DE- CISIONES EN LOS JUEGOS DEPORTIVOS}

\section{Resumen}

La Praxiología Motriz consiste en una teoría científica que se dedica en analizar el funcionamiento de las prácticas motrices, tematizando conocimientos referentes a su lógica interna, como el praxema, modelo operacional que hace referencia al proceso comunicativo de los jugadores. De ese modo, esta investigación objetiva relacionar el praxema con las interacciones motrices de comunicación y contracomunicación, así apuntando sus implicaciones en los procesos de lectura de juego y toma de decisiones en los Juegos Deportivos de cooperación y oposición. Para tanto, se ha realizado una investigación teórica, de naturaleza exploratoria por medio de la cual se ha constatado que el praxema auxilia o dificulta la lectura de juego y la toma de decisión, dependiendo de la interacción motriz establecida entre los jugadores, se presenta como un importante elemento para actuar en el juego.

Palabras Clave: Praxema. Praxiología Motriz. Interacciones Motrices. Juegos Deportivos.

\section{Referências}

COSTA, R. D. Evolução das regras do voleibol. 1999. 76 f. Monografia (Curso de Bacharelado em Treinamento em Esportes) - Curso de Educação Física, Universidade Estadual de Campinas (UNICAMP), Campinas, 1999.

DEMO, P. Metodologia científica em ciências sociais. 3. ed. São Paulo: Atlas S.A., 1995.

GARGANTA, J.; OLIVEIRA, J. Estratégia e tática nos jogos desportivos coletivos. In: OLIVEIRA, J.; TAVARES, F. (Org.). Estratégia e tática nos jogos desportivos coletivos. Portugal: Minerva, 1996. p. 7-23.

GIL, A. C. Métodos e técnicas de pesquisa social. 6. ed. São Paulo: Atlas, 2008.

GRAÇA, A.; MESQUITA, I. A investigação sobre os modelos de ensino dos jogos desportivos. Revista Portuguesa de Ciências do Desporto, Portugal, v. 7, n. 3, p. 401-421, 2007.

GRECO, P. J. Métodos de ensino-aprendizagem-treinamento nos jogos esportivos coletivos. In: GARCIA, E. S.; LEMOS, K. L. M. (Org.). Temas atuais VI - Educação Física e esportes. Belo Horizonte: Health, 2001. p. 48-72.

GRECO, P. J.; BENDA, R. N. Iniciação esportiva universal. Belo Horizonte: UFMG, 2001.

JIMÉNEZ JIMÉNEZ, F. Análisis estructural de las situaciones de enseñanza en los deportes colectivos. Acción Motriz Tu revista digital, Gran Canaria, n. 6, p. 39-57, 2011.

LAGARDERA, F.; LAVEGA, P. Introducción a la Praxiología Motriz. Barcelona: Paidotribo, 2003.

MATIAS, C. J. A. S. O conhecimento tático declarativo e a distribuição de jogo do levantador de voleibol: da formação ao alto nível. 2009. 260 f. Dissertação (Mestrado em Ciências 
do Esporte) - Curso de Educação Física, Escola de Educação Física, Fisioterapia e Terapia Ocupacional, Universidade Federal de Minas Gerais (UFMG), Belo Horizonte, 2009.

MATIAS, C. J. A. S.; GRECO, P. J. Cognição e ação nos jogos esportivos coletivos. Ciências e Cognição, Minas Gerais, v. 15, n. 1, p. 252-271, 2010.

De Morgan ao voleibol moderno: o sucesso do Brasil e a relevância do levantador. Revista Mackenzie de Educação Física e Esporte, São Paulo, v. 10, n. 2, p. 49-63, 2011. PARLEBAS, P. Juegos, deporte y sociedad. Léxico de Praxiología Motriz. Barcelona: Paidotribo, 2001.

Perspectivas para una Educación Física moderna. Málaga: Unisporte, 1987.

PIMENTEL, R. M.; GALATTI, L. R.; PAES, R. R. Pedagogia do esporte e iniciação esportiva tardia: perspectivas a partir da modalidade basquetebol. Pensar a Prática, Goiânia, v. 13, n. 1, p. 1-15, 2010.

RIBAS, J. F. M. Praxiologia Motriz e voleibol: elementos para o trabalho pedagógico. Ijuí: Unijuí, 2014.

SALVADOR, A. D. Métodos e técnicas de pesquisa bibliográfica. Porto Alegre: Sulina, 1986.

SERENINI, A. L. P.; FREIRE, A. B.; NOCE, F. Voleibol. In: GRECO, P. J. (Org.). Iniciação esportiva universal: metodologia da iniciação esportiva na escola e no clube. Belo Horizonte: Ed. UFMG, 1998. p. 249-284. (2. vol.).

URIBE PAREJA, I. D. Iniciación deportiva y Praxiología Motriz. Educación Física e Deporte, v. 19, n. 2, p. 69-74, 1997.

VICARI, I. R.; VERMELHO, E.; VIANA, H. B. A evolução do voleibol no Brasil, a partir da Superliga. EFDeportes.com, Revista Digital, Buenos Aires, v. 17, n. 175, 2012.

Endereço para correspondência:

raquelvvallente@ hotmail.com

Raquel Valente de Oliveira

Universidade Federal de Santa Maria,

Centro de Educação Física e Desportos, Departamento de Desportos Coletivos.

Av. Roraima

Cidade Universitária

97119-000 - Santa Maria, RS - Brasil 